\section{NOTES ON SULPHONAL.}

BY HENRY SUTHERLAND, M.D., PHYSICIAN TO THE ST. GEORGE'S (HANOVER-SQUARE) DISPENSARY.

AFTER repeated trials of sulphonal in various forms of insanity, I have come to the conclusion that in chronic cases associated with recurrent attacks of excitement sulphonal is a most valuable remedial agent, producing sleep, not only on one occasion, but also on two or three nights following its administration. In this form of insanity it also considerably allays excitement during the day, although it may have been given once only as a soporific at bedtime. My experience of its advantages in other forms of mental disease (and especially in continued chronic mania, as opposed to recurrent chronic mania) is less satisfactory.

I. In chronic mania with recurrent attacks of excitement the good effects of sulphonal are very conspicuous.

CASE 1.--Mr. B. R-, aged forty-seven. Usually very quiet. Has attacks of noisy excitement and sleepless nights at irregular intervals. Bromide and chloral in large doses have been given with but slight effect. One dose of thirty grains of sulphonal quiets him at once; not only during the night on which it is taken, but also on the two or three nights following. Strangely, while at the seaside this dose produced little or no effect.

CASE 2.-Mr. L. C-_-, aged seventy. Recurrent mania, with restless nights. Owing to advanced age bromide and chloral do not seem to be indicated. Takes twenty grains of sulphonal now habitually every al ternate night, the result being a long refreshing sleep with two or three quiet nights to follow.

CASE 3.-Mrs. G. M-, aged sixty-seven. Recurrent mania with depression between the attacks. Formerly she was very violent. Bromide, chloral, opium, and all sedatives failed to quiet her until antimony was tried, which had a good effect. Owing to advancing age and the fact that she has a dilated heart, it is thought dangerous to prescribe this remedy any longer. The symptoms, too, are now limited to using bad language and shouting, her attacks upon her attendants being discontinued. Fifteen grains only of sulphonal produced sleep on one night and again on the two nights following, and also a condition of quietude during the day. If not given every three days sleep leaves her and the excitement returns.

II. In chronic mania with continuous, unbroken excitement the effects of sulphonal are uncertain, and the maniacal symptoms seem to be increased during the day.

CASE 4.-Mr. C. R_-, aged thirty-four. Chronic mania (folie circulaire). Continually in a restless condition. Very dirty. Sleeps badly. Bromide and chloral have failed. One dose of thirty grains of sulphonal quieted him for a short time, but subsequent doses have had little or no effect.

CASE 5.-Miss B. D-, aged twenty three. Chronic mania. Never talks. Attacks the attendants impulsively. Sleeps very badly. Bromide produces rash. Sulphonal was tried (fifteen to thirty grains). On some nights she sleeps badly after sulphonal, and on other nights she sleeps well without it. With one exception only she was always more excited during the day after taking this sedative.

CASE 6.-Miss G. A—, aged fifty-two. Chronic mania, with never-ceasing restlessness and moaning. Began with twenty grains. Very stupid the day after this small dose. Slept well that one night, but not well subsequently. Dose increased to thirty grains, and on one occasion to fifty grains. She had no sleep after this large dose. Coördination was much affected. She rolled about in walking next day as if intoxicated.

CASE 7.-Miss G. W-, aged thirty-four. Chronic mania, with violence. Once slept nine hours after fifteen grains; on another occasion slept only two hours after twenty grains. Thirty grains of sulphonal sometimes produce sleep, sometimes have no effect. More excited during the day after taking the drug.

III. Effects of sulphonal in other Jorms of insanity.

CASE 8.-Mr. G. T-_, aged forty. Organic dementia, with hemiplegia. Very restless at night. Ten grains were given on one occasion with good effect. Being almost moribund, it is not thought advisable to continue the sedative.
IV. Incipient general paralysis, with very restless nights. CASE 9.-This patient derived benefit from thirty grains of sulphonal taken one night; also on the following two nights. Took several doses, and it has never failed.

V. Sane patient. Bad effects of sulphonal.

CASE 10.-W. B-, aged twenty-six. Night watch. Being new to the duty was unable to sleep by day. Took thirty grains of sulphonal. Slept eight or nine hours, but woke with a splitting headache. Thirty grains were tried on a second occasion with the same result.

VI. Sane patient. Good effects of sulphonal.

CASE 11.-This patient had a severe cold, with high temperature and sleepless nights. Antipyrin was taken during the day. Sulphonal (thirty grains) taken nightly produced excellent effects.

\section{Modes of Administration.}

After a repeated series of experiments I find sulphonal (in the proportion of thirty grains to one ounce of the menstruum) to be insoluble in cold water, brandy, sherry, ether, nitric acid, and liquor potassa. It is soluble in all these menstrua if boiling, but rapidly precipitates on cooling. It remains in solution far longer in brandy than any other liquid, and might be advantageously given by mixing boiling brandy with sulphonal in solution with hot beeftea, which is, however, a nauseous compound. It is difficult to dissolve in any case, and is more appropriately administered in the solid form, as it is quite tasteless ; nor does it burn the mouth as chloral does. It mav be conveniently given as follows:- $(\alpha)$ In warm beatenup eggs and milk; but the mixture must be well stirred before taken, or the drug will sink to the bottom. (b) In stewed fruit, with plenty of juice and white pounded sugar. (c) In milk puddings, either mixed with the pudding or with the sugar given with the pudding. (It has been tried in the gravy of meat, but is usually detected by the patient.) (d) In hot soup it is freely soluble, but the mixture must not be allowed to cool, or the drug will be found as a deposit at the bottom of the basin. (e) May be given also between two thin slices of bread-and-butter. A few grains of calomel may be added if necessary. Both drugs are tasteless. $(f)$ Might be given made up in a confection or in jam. $(g)$ With patients who do not refuse medicine the following formula may be used:- Sulphonal, $20 \mathrm{gr}$. ; pulv. tragacanth., $2^{0} \mathrm{gr}$. ; syrup. aurantii, $1 \mathrm{dr}$.; aquam ad $1 \mathrm{oz}$. The draught to be well shaken. (This formula is from Mr. E. T. Hall.)

\section{Conclusions.}

Sulphonal is a most valuable sedative in chronic insanity with recurrent attacks of excitement. It is, however, somewbat curious that, in recurrent excitement, the drug should prove so efficacious, whilst in continued excitenent (a form strongly resembling recurrent excitement) the $\epsilon$ fiests should be not only slightly marked but also apparently in jurious, by increasing the state of excitement in the patient on the following day. The lesson to be learnt from a suidy of the effects of sulphonal is that we ought to endeavour to ascertain in what form of alienation and under what particular conditions this or that individual drug is indicated. It is only by the application of one special remedy to a special symptom, or by a mixture of remedies appropriately chosen to a mixture of symptoms, that we can hope to gain any advance in the empirical treatment of insanity.

\section{SULPHONAL IN THE INSOMNIA OF TYPHUS.}

\section{By C. KNOX BOND,}

RESIDEXT MEDICAL OHICER, CITY FOSPITAL, SOUTIS IXVERPOOL.

A DRUG which will induce sleep in typhus fever (and yet avoid the tendency of some other hypnotics, notably opiates, to cause stupor and allied conditions leading $u_{b}>$ to coma), and further which can be given with confidence when these conditions are already to some extent present, substituting natural sleep for semi-stupor, wonld be of extreme value in the treatment of this disease. Sulphonal could scarcely be submitted to a more severe test as regards its harmless, sleep-causing powers than when tried in this direction, and in estimating its worth the following analysis of notes of twenty-three cases in which sleeplessness occurred as a prominent symptom among a total of serenty- 